\title{
Effect of the gynosaponin on methane production and microbe numbers in a fungus-methanogen co-culture*
}

\author{
X.F. Wang, S.Y. Mao, J.H. Liu, L.L. Zhang, Y.F. Cheng, W. Jin \\ and W.-Y. Zhu ${ }^{1}$
}

\author{
Laboratory of Gastrointestinal Microbiology, Nanjing Agricultural University \\ Nanjing 210095, P.R. China
}

(Received 2 November 2010; revised version 9 May 2011; accepted 18 June 2011)

\begin{abstract}
This study investigated the effect of saponins gypenoside (gynosaponins) on methane production and microbe numbers in a co-culture of a fungus, Piromyces sp. F1, and a methanogen, Methanobrevibacter sp.. Two co-culture systems were used: with methanogen (co-culture I) and without methanogen (co-culture II; methanogen growth inhibited by chloramphenicol). Each co-culture system was treated with $0,50,100$ or $200 \mathrm{mg}$ gynosaponins/l culture medium. Gas production, methane concentration and volatile fatty acid concentration (VFA) were measured for each treatment group. The numbers of anaerobic fungi and methanogen were quantified by real time PCR. The results showed that, compared with the control, gynosaponin significantly reduced the gas production, methane concentration, methane to TVFA ratio (total volatile fatty acid), TVFA concentration, number of fungi (except for $50 \mathrm{mg}$ dose of gynosaponin in co-culture I) and number of methanogens. Methane was not detected in co-culture II. The individual VFAs proportion of TVFA were not affected by gynosaponins in either of the co-cultures. The $\mathrm{pH}$ was higher in both co-cultures than that of the control $(\mathrm{P}<0.01)$. These data suggest that gynosaponins has the potential for being used as feed additive to modulate the ruminal fermentation, inhibit the methanogen growth and reduce methane production.
\end{abstract}

KEY WORDS: fungus-methanogen co-culture, gynosaponins, methane, microbial population, in vitro

\footnotetext{
* Supported by the National Natural Science Foundation of China, 30530560

${ }^{1}$ Corresponding author: e-mail: zhuweiyun@njau.edu.cn
} 


\section{INTRODUCTION}

Methane production from ruminants has been identified as the single largest source of anthropogenic $\mathrm{CH}_{4}$ (Mathison et al., 1998). Livestock emit methane as part of their natural digestive processes. The rumen is the home to billions of microbes, including bacteria, methanogens, protozoa and fungi. These microbes breakdown feed to produce volatile fatty acids (VFAs), carbon dioxide, ammonia and methane. Rumen anaerobic fungi are the major degrader of plant fibre and produce formate, acetate, lactate, ethanol, $\mathrm{CO}_{2}$ and $\mathrm{H}_{2}$. Anaerobic fungi and methanogens can form methane producing co-cultures when grown together in batch culture on recalcitrant cellulosic substrates (Bauchop and Mountfort, 1981; Cheng et al., 2006, 2009). Co-culture of anaerobic fungi and methanogens could enhance fibre degradation and methane production by shifting fungal product formation away from more oxidized end-products, such as lactate and ethanol and towards production of more reduced products such as formate and acetate. Formate is the preferred growth substrate of methanogens in the rumen and in co-culture and although acetate is not used extensively for methane production in the rumen ecosystem, it is also an effective methanogenic substrate (Bauchop and Mountfort, 1981; Teunissen et al., 1992; Nakashimada et al., 2000). Thus, anaerobic fungi and methanogen association plays an important role in methane emission in the rumen.

Plant extracts with high concentrations of secondary metabolites have the potential to reduce methane production (Cheeke, 1996; Staerfl et al., 2010; Szumacher-Strabel et al., 2010). Saponins are high-molecular-weight glycosides in which sugars are linked to a hydrophobic aglycone (sapogenin) which may be triterpenoid or steroidal in nature (Teferedegne et al., 1999; Jung et al., 2004). The effect of saponins on ruminal anaerobic fungi are well documented in mixed microbial fermentation (Kostyukovsky et al., 1991; Osbourn, 1996; Lee et al., 2000; Mao et al., 2010). In vitro fungi numbers are reduced by yucca saponin (Wang et al., 2000) and saponin rich Sesbania pachycarpa supplementation (Muetzel et al., 2003). No fungi RNA could be detected in the presence of MS (saponin containing a methanol extract of Sapindus rarak) higher than $1 \mathrm{mg} / \mathrm{ml}$ and methanogen RNA concentration was reduced by a higher concentration of MS $(4 \mathrm{mg} / \mathrm{ml}$ ) (Wina et al., 2005). However, these studies mainly focused on the effect of saponins on fungi numbers and the role of co-culture of fungi and methanogens in methane production was not studied. The co-culturing of anaerobic fungi with methanogen may be a useful way to estimate the bioconversion of cellulose fibre to methane. Thus, the objective of this study was to investigate the effect of gynosaponins, which is derived from Gynostemma pentaphyllum Makino 
and contains dammarane sapogenins, on methane production, fermentation characteristics and cell numbers in fungus-methanogen co-cultures.

\section{MATERIAL AND METHODS}

\section{Inocula}

The inoculum in this study was a natural co-culture of an anaerobic fungus associated with methanogen. Firstly, a mixed co-culture of anaerobic fungi and methanogen from goat rumen content was obtained (Cheng et al., 2006, 2009). The mixed co-culture was then purified by rolling-tube to obtain a single anaerobic fungus with methanogen. The anaerobic fungus in the natural coculture was identified as Piromyces sp. F1 and the associated methanogen was identified as Methanobrevibacter sp. (Cheng et al., 2009). The isolation procedure involved 5-fold serial dilutions of fresh rumen contents from a sacrificed goat. The dilution series was made in a complex medium under anaerobic conditions, as described by Davies et al. (1993) (medium C: 15\% clarified rumen fluid, $2.5 \mathrm{~g} \cdot \mathrm{l}^{-1}$ yeast extract, $10 \mathrm{~g} \cdot \mathrm{l}^{-1}$ trypticase peptone, $6 \mathrm{~g} \cdot \mathrm{l}^{-1} \mathrm{NaHCO}_{3}$, and a basal salts solution) with cellobiose as the energy source $\left(5.0 \mathrm{~g}^{-1} \mathrm{l}^{-1}\right)$ and $1 \%(\mathrm{v} / \mathrm{v})$ antibiotic mixture containing streptomycin sulphate and penicillin (each at $5 \mathrm{mg}^{-1}$ in the stock solution). These culture solutions were then subcultured anaerobically into fresh tubes of medium $\mathrm{C}$ with cellobiose. Axenic cultures of the fungi were picked from roll tube agar using the technique of Joblin (1981) and were maintained in $10 \%$ glycerol stored under liquid nitrogen. The roll tube medium contained $1.5 \%(\mathrm{w} / \mathrm{v})$ agar in addition to the other ingredients used by Orpin (1976). One of symbionts was identified as the monocentric fungi Piromyces associated with the methanogen Methanobrevibacter thaneri strain CW, which was selected as the inocula in this study. Bacteria in each culture were not detected by PCR with general primers 968f/1401r (Su et al., 2008) and protozoa were not observed by optical invert microscope.

\section{Preparation of saponin and experimental design}

The effect of gynosaponins extracted from Gynostemma pentaphyllum Makino on fungal fermentation was evaluated in an in vitro batch culture under anaerobic conditions. The gynosaponins powder $(98 \%$ gynosaponin, a group of saponins) was provided by Kangwei Bioengineering Ltd. (China). About 90 kinds of gynosaponin have been also isolated from G. pentaphyllum (Cui et al., 1999). Four different doses of gynosaponin were added to each co-culture system: 0, 50, 100 and $200 \mathrm{mg} / \mathrm{l}$ of medium (Hu et al., 2005; Wang et al., 2011). The 
fermentation was conducted in 160-ml serum bottles containing $90 \mathrm{ml}$ medium (Davies et al., 1993) and 0.8 g rice straw (ground through a $3 \mathrm{~mm}$ screen), in triplicate for each treatment (Singh et al., 2001; Hu et al., 2005; Garcia-Gonzalez et al., 2007). Bottles were flushed with $\mathrm{CO}_{2}$ before sealing with rubber stoppers and aluminum caps, and sterilized at $121^{\circ} \mathrm{C}$ for $15 \mathrm{~min}$. Half the bottles were injected with $1 \mathrm{ml}$ chloramphenicol inhibiting the growth of methanogens (Cheng et al., 2009; Fernandes et al., 2010; Ravella et al., 2010) and the other half were injected with $1 \mathrm{ml}$ sterilized medium. The inoculum was cultured in four serum bottles until the straw floating and incorporated four bottles of inocula into one $500 \mathrm{ml}$ vessel under obligated anaerobic and axenic condition. The inocula was uniformly mixed and ten million litre of inocula was draw out and inoculated into the serum bottles. All of serum bottles were incubated at $39^{\circ} \mathrm{C}$ for 4 days.

\section{Analysis of fermentation end products}

During incubation at $39^{\circ} \mathrm{C}$, the accumulation of the gas produced was measured at $0,12,24,30,36,48,72$ and $96 \mathrm{~h}$ using the pressure transducer technique of Theodorou et al. (1995). The accumulative gas production approach almost the maximum after $96 \mathrm{~h}$ fermentation according to our preliminary study, wherein the fermentation were terminated. From the head-space of each serum bottle, $50 \mu \mathrm{l}$ of gas sample was drawn out by a gastight syringe to measure methane concentrations according to the method described by $\mathrm{Hu}$ et al. (2005).

After $96 \mathrm{~h}$ incubation, the experimental culture supernatants were collected and the $\mathrm{pH}$ were analysed immediately using a portable $\mathrm{pH}$-meter with a glass electrode (Ecoscan $\mathrm{pH} 5$, Singapore). One milliliter of a solution containing $250 \mathrm{~g} / 1 \mathrm{metaphosphoric} \mathrm{acid} \mathrm{(wt/wt)} \mathrm{and} 6.4 \mathrm{~g} / 1$ crotonic acid (wt/wt) was added to $5 \mathrm{ml}$ of fermentation fluid and frozen at $-20^{\circ} \mathrm{C}$ for the VFA analysis by the method of Jouany (1982). Samples were thawed at ambient temperature and centrifuged at $12.000 \mathrm{~g}$ for $5 \mathrm{~min}$ at $4^{\circ} \mathrm{C}$ in a micro-centrifuge. VFA analysis was carried out on the supernatants $(0.6 \mu \mathrm{l})$, with crotonic acid included as an internal standard (Cottyn and Boucque, 1968), using a flame ionization detector and a Capillary Column (Supelco, Column No.34292-07 B, $30 \mathrm{~m} \times 0.32 \mathrm{~mm} \times$ $0.25 \mu \mathrm{m}$ film thickness, U.S.) with an injector/detector temperature of $180^{\circ} \mathrm{C} / 180^{\circ} \mathrm{C}$, a column temperature of $140^{\circ} \mathrm{C}$ and a gas flow rate of $30 \mathrm{ml} / \mathrm{min}$.

Ten milliliters of homogenized fermentation contents were collected for DNA extraction using the modified CTAB method (hexadecyltrimethylammonium bromide) of Doyle and Doyle (1987). The samples were centrifuged at $12.000 \mathrm{~g}$ for $10 \mathrm{~min}$ and the supernatants were discarded. The sediments were resuspended in $800 \mathrm{ml} \mathrm{CTAB}$ buffer (0.1 M Tris HCl, pH 8.0, $1.4 \mathrm{M} \mathrm{NaCl}, 0.02 \mathrm{M}$ EDTA, 2\% CTAB), beaten for 4 min using a bead-beater (Biospec Products, Bartlesville, OK, USA) and incubated at $70^{\circ} \mathrm{C}$ for $20 \mathrm{~min}$. Chloroform $(500 \mathrm{ml})$ was added and the 
samples were vortexed for $1 \mathrm{~min}$ and centrifuged at $13.000 \mathrm{~g}$ for $10 \mathrm{~min}$ at ambient temperature. The upper aqueous layers $(500 \mathrm{ml})$ were carefully removed and mixed with $300 \mathrm{ml}$ isopropanol. After centrifuging at $13.000 \mathrm{~g}$ for $10 \mathrm{~min}$, the resulting DNA pellets were washed with $1 \mathrm{ml}$ iced $\left(-20^{\circ} \mathrm{C}\right) 70 \%$ ethanol, centrifuged again (13.000 $\mathrm{g}$ for $20 \mathrm{~min}$ ) and, after removal of the ethanol, resuspended it in $50 \mathrm{ml}$ TE buffer ( $\mathrm{pH} 8.0$ ) and stored at $-20^{\circ} \mathrm{C}$ until required.

Real-time PCR assay for quantification of the fungus and methanogen

Real-time PCR was performed on an Applied Biosystems 7300 Real-Time system (Applied Biosystems, CA, USA) using fungal 18S rRNA gene and methanogen mcrA gene-specific primers (Denman et al., 2006, 2007). A reaction mixture (20 1) consisted of 101 of IQ SYBR Green Supermix (Bio-Rad, CA, USA), $0.2 \mathrm{M}$ of each primer set and 11 of the template DNA. Measurements were done in triplicate for each run including a negative control (Boechaert et al., 2008). The amount of DNA in each sample was spectrophotometrically determined in triplicate using a GeneQuant pro RNA/DNA calculator (Amersham Biosciences, Bath, UK), and the mean values were calculated. Standard curves for the fungus and methanogen were generated using the serially diluted corresponding gene amplicons obtained from the same co-culture. DNA concentration of the PCR product measured on GeneQuant pro RNA/DNA calculator can be directly related to copy numbers using the following equation:

$$
\text { copy number/ } \mu \mathrm{l}=(\mathrm{C} / \mathrm{X}) \times 0.912 \times 10^{12}
$$

where: C - DNA concentration measured (ng/ $\mu 1) ; \mathrm{X}$ - PCR fragment or plasmid length (bp/copy), by using the average weight of a bp) (provided by Wageningen Institute of Animal Sciences, the Netherlands).

PCR was performed under the following cycle conditions: one cycle of $50^{\circ} \mathrm{C}$ for $2 \mathrm{~min}$ and $95^{\circ} \mathrm{C}$ for $2 \mathrm{~min}$ for the initial denaturation, and 40 cycles at $95^{\circ} \mathrm{C}$ for $15 \mathrm{~s}$ and $60^{\circ} \mathrm{C}$ for $1 \mathrm{~min}$ for the primer annealing and product elongation (Denman et al., 2006). Fluorescence detection was performed at the end of each denaturation and extension step. Specificity of the amplified products was confirmed by melting temperatures and dissociation curves after each amplification. Amplification efficiencies for each primer pair were investigated by examining a dilution series of the fungus and methanogen on the same plate in triplicate.

\section{Statistical analysis}

Statistical analysis was carried out using one-way ANOVA in the statistical software package SPSS (version11.0; SPSS Inst. Inc. Cary, NC). The dosage of gynosaponins was the source of variation, and the linear or quadratic effects of 
increasing dosage of gynosaponins were determined using polynomial contrasts. The statistical model included the effects of treatment and incubation time as the repeated factors. All values were expressed as means of three replicates. Significant differences were declared when $\mathrm{P}<0.05$.

\section{RESULTS}

\section{Effect of gynosaponins on gas production and methane emission}

The effect of gynosaponins on the end products of in vitro co-culture fermentation, gas production and methane concentration are shown in Table 1

Table 1. Effect of gynosaponins supplementation on fermentation characteristics of the fungusmethanogen co-culture in $96 \mathrm{~h}$ incubation

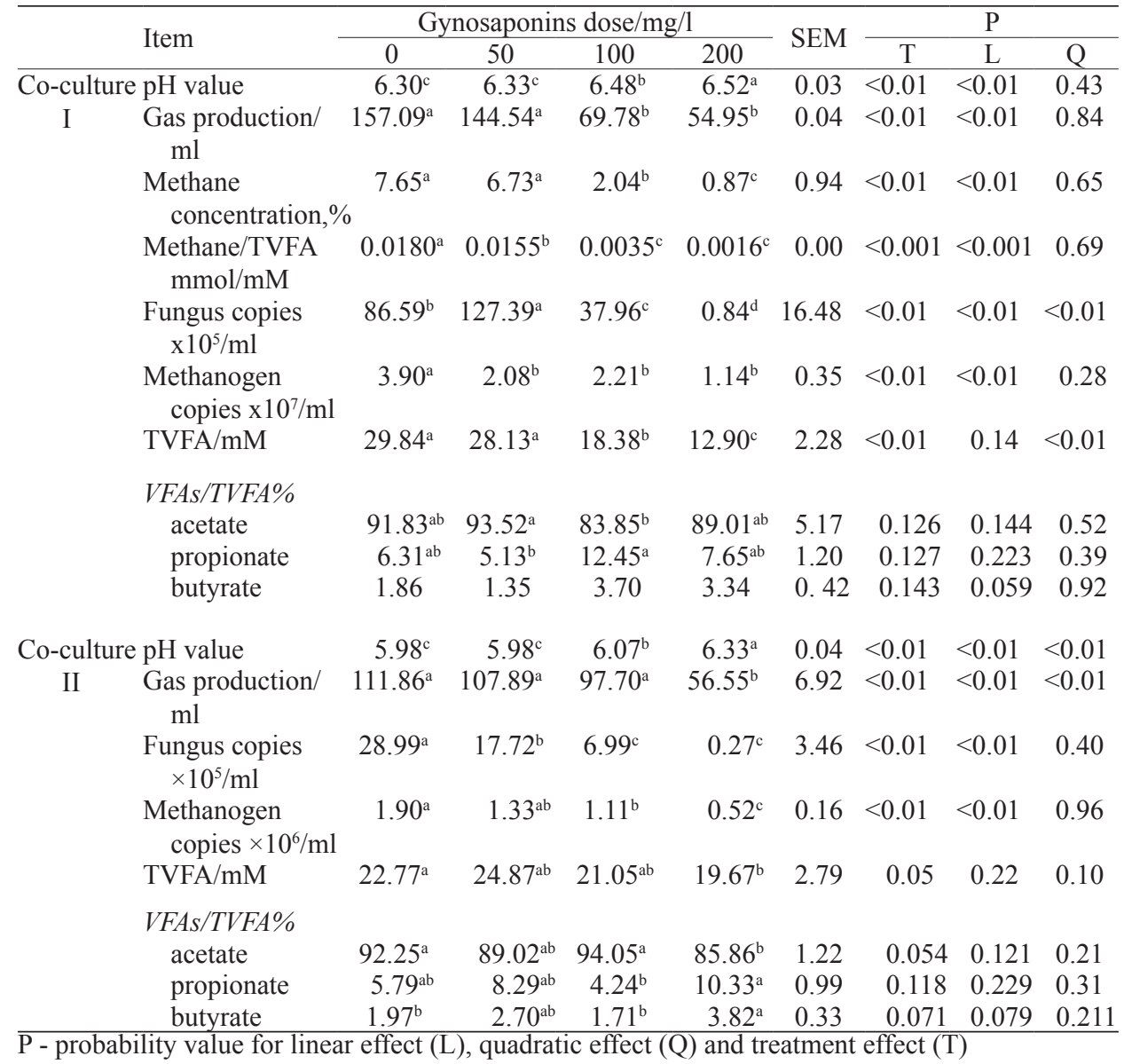


and Figure 1. In co-culture I, as gynosaponins level increased, the gas production and methane concentration linearly decreased $(\mathrm{P}<0.01)$. After incubation for $96 \mathrm{~h}$, the gas production differed significantly between the co-cultures treated with 100 and $200 \mathrm{mg}$ gynosaponins (Figure 1A). In co-culture I, gas production in the 100 and $200 \mathrm{mg}$ gynosaponins groups was lower than that of control. In co-culture I, the gas production was only significantly reduced by the $200 \mathrm{mg}$ gynosaponins dose. There was no significant variation between treatments of the 50 and $100 \mathrm{mg}$ gynosaponins doses $(\mathrm{P}>0.05$; Figure 1C). Significant linear and quadratic patterns were observed between gas production and gynosaponin doses. As compared with the control, methane concentrations in culture I were reduced

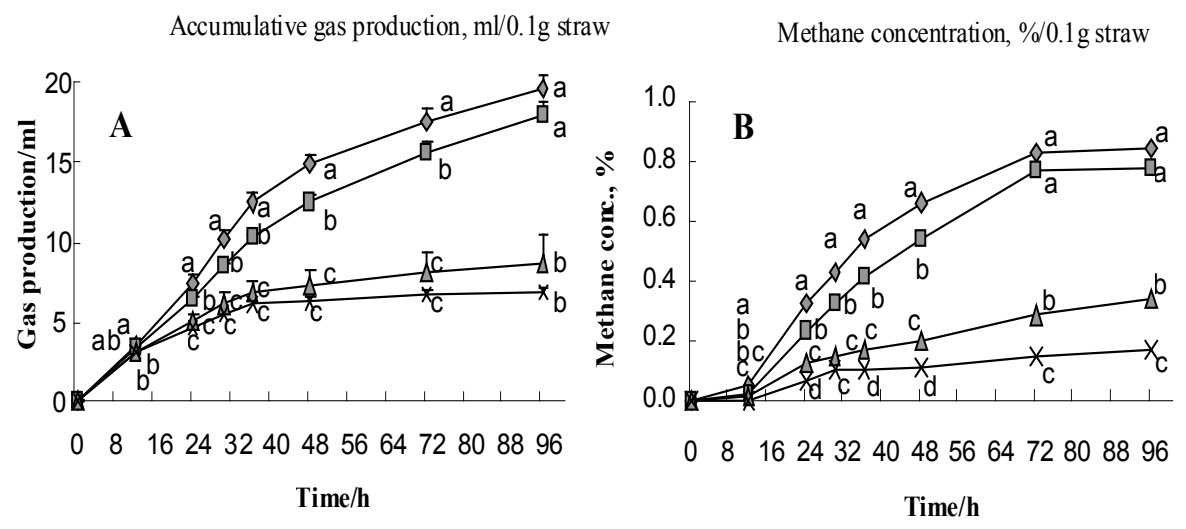

Accumulative gas production, $\mathrm{ml} / 0.1 \mathrm{~g}$ straw

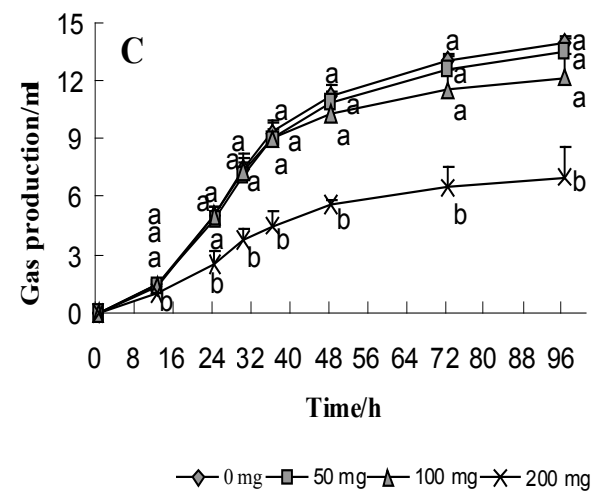

Figure 1. Fitted curves of cumulative gas production $(\mathrm{ml})$ and methane concentration (\%). A - Cumulative gas production of co-culture I. B - methane concentration of co-culture I. C - Cumulative gas production of co-culture II; a,b,c in these legends denoted are significantly different at $\mathrm{P}<0.05$ level 
$(\mathrm{P}<0.05$ or $\mathrm{P}<0.01)$ by the addition of gynosaponin except for the $50 \mathrm{mg}$ dose at 72 and $96 \mathrm{~h}$ (Figure 1B). The methane to TVFA ratio decreased by gynosaponins addition $(\mathrm{P}<0.001)$. A linear pattern was observed between the methane to TVFA ratio and gynosaponin dose. Methane was not detected in co-culture II due to the complete inhibition of methanogen by chloramphenicol.

\section{Effect of gynosaponins on volatile fatty acid concentrations and $p H$}

In co-culture I, TVFA concentrations decreased quadratically $(\mathrm{P}<0.01)$ with increasing gynosaponins concentration $(\mathrm{P}<0.01)$. In co-culture II, saponin addition caused a significant reduction in TVFA concentration $(\mathrm{P}=0.05)$. Gynosaponins had no effect on the individual VFAs proportion of TVFA in either of the cocultures $(\mathrm{P}>0.05)$. The $\mathrm{pH}$ increased in both co-culture I (linear pattern, $\mathrm{P}<0.01$ ) and in co-culture II (linear and quadratic patterns, $\mathrm{P}<0.01$ ) as gynosaponins level increased.

\section{Effects of gynosaponins on numbers of fungi and methanogens}

The real-time PCR efficiencies of fungus and methanogen primers were 96.85 and $100.92 \%\left(\mathrm{R}^{2}=0.999\right.$ and 0.991$)$, respectively. The copies of methanogenic mcrA genes and fungal 18S rRNA genes in the co-cultures were determined by qPCR (Table 1). In co-culture I, the fungi numbers were highest for $50 \mathrm{mg}$ gynosaponins dose $(\mathrm{P}<0.05)$ in both co-culture systems and were drastically reduced by the 100 and $200 \mathrm{mg}$ gynosaponins doses $(\mathrm{P}<0.01)$. The fungi numbers in co-culture II decreased linearly as gynosaponins dose increased $(\mathrm{P}<0.01)$. The methanogen numbers in both of the co-culture systems were linearly reduced $(\mathrm{P}<0.01)$ as gynosaponins level increased.

\section{DISCUSSION}

Effect on gas and methane production. Theodorou et al. (1995) considered many factors contribute to the generation of gas by fermenting cultures, including the type of microorganisms involved, the rate of growth, the concentration and nature of the growth-limiting nutrient. Thus, gas production was closely related to the microbial growth and the digestion of fermentation substrates. In the current study, the reduction of gas production might be due to the decreased activity or number of fungi, which resulted in decreased digestion of substrates. Wang et al. (2000) also found that steroidal saponins inhibited the digestion of filter paper by 
ruminal fungi. In the current study, the gas production pattern in the two co-culture systems occurred differently, with reduced gas production observed with only the $200 \mathrm{mg}$ gynosaponin dose in co-culture II compared to the control. This difference might be caused by the fungus having reduced sensitivity to gynosaponin when co-cultured without methanogens. The inhibition of fungal metabolism resulted in a decrease in hydrogen supply and further reduced methane production. This result was inconsistent with the observation of Staerfl et al. (2010) that yucca saponin have no effect on a methane production. It is deduced that gas production by fungi-methanogen co-cultures differs in the presence or absence of methanogens and gynosaponin can curb methane production in rumen.

Effect on fermentation characteristics. In the present study, the TVFA and acetate concentration were significantly reduced due to a reduction in fungi numbers and activity by gynosaponins. This result agrees with the observations of Lu and Jorgensen (1987), which suggested that lucerne saponin, tested on an in vitro fermentation of mixed ruminal microorganisms, resulted in general inhibition of rumen microbial fermentation. However, it is inconsistent with our preliminary observation that gynosaponins had a minor effect on VFA concentration in goats. The individual VFAs proportion of TVFA was unchanged and inconsistent with the observation of Staerfl et al. (2010) that the acetate proportion of TVFA was reduced by yucca saponins and the observation of Dong et al. (2010) that an increase of the propionate concentration was observed by lucerne extract. Due to the different structure of saponins, the saponins displayed different bioactive properties (Hu et al., 2005; Pen et al., 2008). Therein, gynosaponins only affected the TVFA concentration and not the individual VFAs proportion of TVFA in the present study. Higher $\mathrm{pH}$ values were observed as gynosaponins dose increased as previously observed in sheep feed yucca saponin (Eryavuz and Dehority, 2004). As the $\mathrm{pH}$ is dependent on the TVFA concentration in the co-culture (Mountfort et al., 1982), the increased $\mathrm{pH}$ in this study might have been a result of the decreased VFA concentration.

Effect on numbers of the fungi and methanogens. The primary mode of action of saponins on fungi is similar to that of polyene antibiotics, and involves the formation of complexes with membrane sterols (Price et al., 1987). This may result in pore formation and loss of membrane integrity, which further leads to low fungal activity and even fungi death. In the present study, due to a potential synergism between fungi and methanogens, the growth of the fungus was increased in the co-culture with methanogens at low dose of gynosaponins (50 mg/l medium). As observed by Diaz et al. (1993), low levels of $S$. rarak saponins have a positive effect on the fungi Chytridiomycetes. The increased fungi numbers in low dose of gynosaponins likely due to the sugar moiety of saponin 
as a nutrient for microorganisms. However, the number of fungal cells decreased quickly as gynosaponins level increased. In our preliminary study, we also found similar changes in the growth of the ruminal fungus as the gynosaponins dose increased. The number of ruminal fungi detected in the sample treated with $200 \mathrm{mg}$ of gynosaponins was about 100 times less than the control, showing it was extremely sensitive to gynosaponins. Wang et al. (2000) also reported that Neocallimastix frontalis and Piromyces rhizinflata were completely inhibited in vitro by Yucca schidigera saponins.

In the present study, the number of methanogens in both co-culture systems were linearly reduced as gynosaponins level increased. This result was inconsistent with the observation of Guo et al. (2008) and Staerfl et al. (2010) that tea saponins and yucca saponin have no effect on a methanogen population in pure culture. The strong toxic effect of gynosaponins was demonstrated most clearly on the methanogens examined, which agreed with our preliminary observation showing its intensively anti-methanogen characteristics in goat rumen. Methanogen copies were detected in culture II, which DNA concentration of methanogen derived from the original inocula.

\section{CONCLUSIONS}

Gynosaponins reduced methane production in the fungus-methanogen coculture with methanogens, confirming the antimicrobial effect of gynosaponins. It is inferred that a reduction in fungi numbers might also contribute to decreased methane emission. The appropriate level of gynosaponins prompted the growth of the fungus in the co-culture with methanogens, but a high level of gynosaponins inhibited the growth of the fungus and methanogen. It was speculated that gynosaponins might have more effect on fermentation in the co-culture system with methanogens. Thus, data of the present experiment suggest the proper gynosaponins has the potential for being used as feed additives in ruminants.

\section{REFERENCES}

Bauchop T., Mountfort D.O., 1981. Cellulose fermentation by a rumen anaerobic fungus in both the absence and the presence of rumen methanogens. Appl. Environ. Microbiol. 42, 1103-1110

Boechaert C., Vlaeminck B., Fievez V., Maignien L., Dijkstra J., Boon N., 2008. Accumulation of trans C18:1 fatty acids in the rumen after dietary algal supplementation is associated with changes in the butyrivibrio community. Appl. Environ. Microbiol. 74, 6923-6930

Cheeke P.R., 1996. Biological effects of feed and forage saponins and their impacts on animal production. Adv. Exp. Med. Biol. 405, 377-385 
Cheng Y.F., Edwards J.E., Allison G.G., Zhu W.Y., Theodorou M.K., 2009. Diversity and activity of enriched ruminal cultures of anaerobic fungi and methanogens grown together on lignocellulose in consecutive batch culture. Bioresour. Technol. 100, 4821-4828

Cheng Y.F., Mao S.Y., Pei C.X., Liu J.X., Zhu W.Y., 2006. Detection and diversity analysis of rumen methanogens in the co-cultures with anaerobic fungi. Acta Microbiol. Sinica 46, 879883

Cottyn B.G., Boucque C.V., 1968. Rapid method for the gas-chromatographic determination of volatile fatty acids in rumen fluid. J. Agr. Food Chem. 16, 105-107

Cui J., Eneroth P., Bruhn J.S., 1999. Gynostemma pentaphyllum: identification of major sapogenins and differentiation from Panax species. Eur. J. Pharm. Sci. 8, 187-191

Davies D.R., Theodorou M.K., Brooks A.E., Trinci A.P.J., 1993. Influence of drying on the survival of anaerobic fungi in rumen digesta and faeces of cattle. FEMS Microbiol. Lett. 106, 59-63

Denman S.E., McSweeney C.S., 2006. Development of a real-time PCR assay for monitoring anaerobic fungal and cellulolytic bacterial populations within the rumen. FEMS Microbiol. Ecol. 58, 572-582

Denman S.E., Tomkins N.W., McSweeney C.S., 2007. Quantitation and diversity analysis of ruminal methanogenic populations in response to the antimethanogenic compound bromochloromethane. FEMS Microbiol. Ecol. 62, 313-322

Díaz A., Avendano M., Escobar A., 1993. Evaluation of Sapindus saponaria as a defaunating agent and its effects on different ruminal digestion parameters. Livest. Res. Rural Dev. 5, 1-6

Dong G.Z., Wang X.J., Liu Z.B., Wang F., 2010. Effects of phytogenic products on in vitro rumen fermentation and methane emission in goats. J. Anim. Feed Sci. 19, 218-229

Doyle J.J., Doyle J.L., 1987. A rapid DNA isolation procedure from small quantities of fresh leaf tissue. Phytochem. Bull. 19, 11-15

Eryavuz A., Dehority B.A., 2004. Effect of Yucca schidigera extract on the concentration of rumen microorganisms in sheep. Anim. Feed Sci. Tech. 117, 215-222

Fernandes E.K.K., Keyser C.A., Rangel D.EN., Foster R.N., Roberts D.W., 2010. CTC medium: A novel dodine-free selective medium for isolating entomopathogenic fungi, especially Metarhizium acridum, from soil. Biol. Control. 54, 197-205

Garcia-Gonzalez R., Lopez S., Fernandez M., González J.S., 2008. Dose-response effects of Rheum officinale root and Frangula alnus bark on ruminal methane production in vitro. Anim. Feed Sci. Tech. 145, 319-334

Guo Y.Q., Liu J.X., Lu Y., Zhu W.Y., Denman S.E., McSweeney C.S., 2008. Effect of tea saponin on methanogenesis, microbial community structure and expression of mcrA gene, in cultures of rumen micro-organisms. Lett. Appl. Microbiol. 47, 421-426

Hu W.L., Liu J.X., Ye J.A., Wu Y.M., Guo Y.Q., 2005. Effect of tea saponin on rumen fermentation in vitro. Anim. Feed Sci. Tech. 120, 333-339

Joblin K.N., 1981. Isolation, enumeration, and maintenance of rumen anaerobic fungi in roll tubes. Appl. Environ. Microbiol. 42, 1119-1122

Jouany J.P., 1982. Volatile fatty acids and alcohol determination in digestive contents, silage juice, bacterial cultures and anaerobic fermentor contents. Sci. Alim. 2, 131-144

Jung H.J., Lee C.O., Lee K.T., Choi J., Park H.J., 2004. Structure-activity relationship of oleanane disaccharides isolated from Akebia quinata versus cytotoxicity against cancer cells and NO inhibition. Biol. Pharm. Bull. 27, 744-747

Kostyukovsky V.A., Okunev O.N., Tarakanov B.V., 1991. Description of two anaerobic fungal strains from the bovine rumen and influence of diet on the fungal population in vivo. J. Gen. Microbiol. 137, 1759-1764 
Lee S.S., Ha J.K., Cheng K.J., 2000. Relative contributions of bacteria, protozoa, and fungi to in vitro degradation of orchard grass cell walls and their interactions. Appl. Environ. Microbiol. 66, 3807-3813

Lu C.D., Jorgensen N.A., 1987. Alfalfa saponins affect site and extent of nutrient digestion in ruminants. J. Nutr. 117, 919-927

Mao H.L., Wang J.K., Zhou Y.Y., Liu J.X., 2010. Effects of addition of tea saponins and soybean oil on methane production, fermentation and microbial population in the rumen of growing lambs. Livest. Sci. 129, 56-62

Mathison G.W., Okine E.K., McAllister T.A., Okine E.K., 1998. Reducing methane emissions from ruminant animals. J. Appl. Anim. Res. 14, 1-28

Mountfort D.O., Asher R.A., Bauchop T., 1982. Fermentation of cellulose to methane and carbon dioxide by a rumen anaerobic fungus in a triculture with Methanobrevibacter $\mathrm{sp}$. Strain RA1 and Methanosarcina barkeri. Appl. Environ. Microbiol. 44, 128-134

Muetzel S., Hoffmann E.M., Becker K., 2003. Supplementation of barley straw with Sesbania pachycarpa leaves in vitro: effects on fermentation variables and rumen microbial population structure quantified by ribosomal RNA-targeted probes. Brit. J. Nutr. 89, 445-453

Nakashimada Y., Marwoto B., Kashiwamura T., 2000. Enhanced 2,3-butanediol production by addition of acetic acid in Paenibacillus polymyxa. J. Biosci. Bioeng. 90, 661-664

Orpin C.G., 1976. Studies on the rumen flagellate Sphaeromonas communis. J. Gen. Microbiol. 94, $270-280$

Osbourn A., 1996. Saponins and plant defence - a soap story. Trends Plant Sci. 1, 4-9

Pen B., Sar C., Mwenya B., Takahashi J., 2008. Effects of Quillaja saponaria extract alone or in combination with Yucca schidigera extract on ruminal fermentation and methanogenesis in vitro. Anim. Sci. J. 79, 193-199

Price K.R., Johnson I.T., Fenwick G.R., 1987. The chemistry and biological significance of saponins in food and feeding stuffs. Crit. Rev. Food Sci. Nutr. 26, 27-133

Ravella S.R., Quiňones T.S., Retter A., Heiermann M., Amonc T., Hobbs P.J., 2010. Extracellular polysaccharide (EPS) production by a novel strain of yeast-like fungus Aureobasidium pullulans. Carbohyd. Polym. 82, 728-732

Singh B., Bhat T.K., Sharma O.P., 2001. Biodegradation of tannic acid in an in vitro ruminal system. Livest. Prod. Sci. 68, 259-262

Staerfl S.M., Kreuzer M., Soliva C.R., 2010. In vitro screening of unconventional feeds and various natural supplements for their ruminal methane mitigation potential when included in a maizesilage based diet. J. Anim. Feed Sci. 19, 651-664

Su Y., Yao W., Perez-Gutierrez O.N., Smidt H., Zhu W.Y., 2008. 16S ribosomal RNA-based methods to monitor changes in the hindgut bacterial community of piglets after oral administration of Lactobacillus sobrius S1. Anaerobe 14, 78-86

Szumacher-Strabel M., Cieślak A., 2010. Potential of phytofactors to mitigate rumen ammonia and methane production. J.Anim. Feed Sci. 19, 319-337

Teferedegne B., McIntosh F., Osuji P.O., Wallace R.J., Newbold C.J., 1999. Influence of foliage from different accessions of the sub-tropical leguminous tree, Sesbania sesban, on ruminal protozoa in Ethiopian and Scottish sheep. Anim. Feed Sci. Tech. 78, 11-20

Teunissen M.J., Kets E.P., Op den Camp H.J., Huis in't Veld J.H., Vogels G.D., 1992. Effect of coculutre of anaerobic fungi isolated from ruminants and non-ruminants with methanogenic bacteria on cellulolytic and xylanolytic enzyme activities. Arch. Microbiol. 157, 176-182

Theodorou M.K., David D.R., Nielsen B.B., Lawrence M.I.G., Trinci P.J., 1995. Determination of growth of anaerobic fungi on soluble and cellulosic substrates using a pressure transducer. Microbiology 141, 671-678 
Wang X.F., Mao S.Y., Zhu W.Y., 2011. Effects of gypenoside on in vitro ruminal microbial methane production and fermentation characteristics. Acta Pratacult. Sinica 20, 52-59

Wang Y., McAllister T.A., Yanke L.J., Cheeke P.R., 2000. Effect of steroidal saponin from Yucca schidigera extract on ruminal microbes. J. Appl. Microbiol. 88, 887-896

Wina E., Muetzel S., Hoffmann E., Makkar H.P.S., Becker K., 2005. Saponins containing methanol extract of Sapindus rarak affect microbial fermentation, microbial activity and microbial community structure in vitro. Anim. Feed Sci. Tech. 121, 159-174 